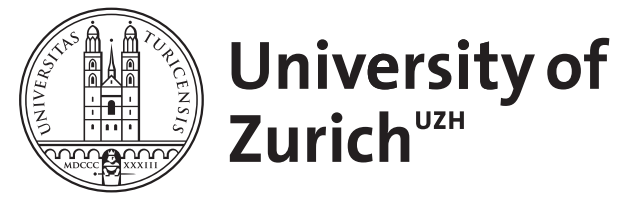

\title{
Towards a non-rationalist inflationist account of intuitions
}

Langkau, Julia

\begin{abstract}
In this paper, I first develop desiderata for an ontology of intuitions on the basis of paradigmatic cases of intuitions in philosophy. A special focus lies on cases that have been subject to extensive firstorder philosophical debates but have been receiving little attention in the current debate over the ontology of intuitions. I show that none of the popular accounts in the current debate can meet all desiderata. I discuss a view according to which intuitions reduce to beliefs, Timothy Williamson's (2004, 2007) account of intuitions as beliefs or inclinations to believe, and traditional rationalist accounts of intuitions. I then show that a widely ignored account of intuitions as appearance states can meet the desiderata best.
\end{abstract}

Posted at the Zurich Open Repository and Archive, University of Zurich

ZORA URL: https://doi.org/10.5167/uzh-68781

Journal Article

Published Version

Originally published at:

Langkau, Julia (2012). Towards a non-rationalist inflationist account of intuitions. Essays in Philosophy, $13(1): 310-335$. 


\section{Essays in Philosophy}

Volume 13

Issue 1 Philosophical Methodology

Article 18

$1-30-2012$

\section{Towards a Non-Rationalist Inflationist Account of Intuitions}

Julia Langkau

University of St. Andrews

Follow this and additional works at: http://commons.pacificu.edu/eip

Part of the Philosophy Commons

Recommended Citation

Langkau, Julia (2012) "Towards a Non-Rationalist Inflationist Account of Intuitions," Essays in Philosophy: Vol. 13: Iss. 1, Article 18.

Essays in Philosophy is a biannual journal published by Pacific University Library | ISSN 1526-0569 | http://commons.pacificu.edu/eip/ 


\title{
Towards a Non-Rationalist Inflationist Account of Intuitions
}

\begin{abstract}
In this paper, I first develop desiderata for an ontology of intuitions on the basis of paradigmatic cases of intuitions in philosophy. A special focus lies on cases that have been subject to extensive first-order philosophical debates but have been receiving little attention in the current debate over the ontology of intuitions. I show that none of the popular accounts in the current debate can meet all desiderata. I discuss a view according to which intuitions reduce to beliefs, Timothy Williamson's $(2004,2007)$ account of intuitions as beliefs or inclinations to believe, and traditional rationalist accounts of intuitions. I then show that a widely ignored account of intuitions as appearance states can meet the desiderata best.
\end{abstract}




\title{
Towards a Non-Rationalist Inflationist Account of Intuitions
}

\section{Julia Langkau, University of St. Andrews}

Published online: 30 January 2012

(C) Julia Langkau 2012

\begin{abstract}
In this paper, I first develop desiderata for an ontology of intuitions on the basis of paradigmatic cases of intuitions in philosophy. A special focus lies on cases that have been subject to extensive first-order philosophical debates but have been receiving little attention in the current debate over the ontology of intuitions. I show that none of the popular accounts in the current debate can meet all desiderata. I discuss a view according to which intuitions reduce to beliefs, Timothy Williamson's $(2004,2007)$ account of intuitions as beliefs or inclinations to believe, and traditional rationalist accounts of intuitions. I then show that a widely ignored account of intuitions as appearance states can meet the desiderata best.
\end{abstract}

\section{What are Intuitions?}

In reflecting on their methodology, philosophers use the term 'intuition' in different ways. Some use it to refer to a source of knowledge, others to a kind of propositional attitude. Some philosophers use it for a priori knowledge only, others for common sense judgments. Psychologists sometimes speak of 'intuition' as an unconscious, gut-guided decision process. ${ }^{1}$ There are even more ways of using the term in ordinary language, some of which occur in philosophy papers - such as the hedging use of 'intuition'. In this paper, I am not concerned with different uses or meanings of the term 'intuition'.

I am interested in the question of what kind of propositional attitudes we are dealing with in some specific philosophical contexts. Cases that have been playing an important methodological role in philosophy are thought experiments. We say we have the 'intuition' that a person in the Gettier Cases against the JTB theory of knowledge has a justified true belief but no knowledge. ${ }^{2}$ We say we have the 'intuition' that colour scientist Mary learns something when she leaves her black and white room and sees something coloured for the first time in her life in Frank Jackson's Mary Case against physicalism. ${ }^{3}$ Other paradigmatic cases are paradoxes such as the Sorites Paradoxes, the Paradox of Emotional Response to Fiction, or the Lottery Paradoxes. In these cases, we

Corresponding Author: J. Langkau

University of St. Andrews

email-j1632@,st-andrews.ac.uk

propositions that constitutes the paradox. I restrict my considerations to instances of the 
say that we have 'intuitions' towards all propositions of the inconsistent set of use of 'intuition' or 'intuitive' in thought experiments and paradoxes (I use ' $p$ is intuitive to $S$ ' synonymously with ' $S$ has the intuition that $p$ ').

Drawing a simplified picture of the current debate over the ontology of intuitions as propositional attitudes, there are two main camps, inflationists and deflationists. Inflationists hold that intuitions are a distinctive class of states. Some inflationists make the further claim that intuitions provide a basic source of a priori knowledge (e.g., Bealer [4], Pust [22]). I will call the latter 'rationalist inflationists'. Deflationists think that intuitions can be reduced to judgments, beliefs, or inclinations to believe. Some deflationists also think that intuitions play no relevant evidential role (e.g., Williamson [35], Deutsch [7]) or no evidential role at all (Earlenbaugh and Molyneux [8]). I will draw attention on what I will call a 'non-rationalist inflationist' account of intuitions according to which intuitions are a distinctive class of mental states but do not provide a source of a priori knowledge. This option has been widely ignored in the current debate over the ontology and epistemic role of intuitions.

In section 2 of this paper, I develop desiderata for an ontology of the states we call 'intuitions' in some paradigmatic cases. These cases reveal certain key phenomena that, other things being equal, an ontology of intuitions should accommodate and explain. A special focus lies on cases that have been subject to extensive first-order philosophical debates but that have been receiving little attention in the current methodological debate over the ontology of intuitions. In the following two sections, I argue that the most obvious strategies to account for these phenomena within a deflationist picture of intuitions fail: in section 3, I examine a simple deflationist view according to which intuitions are just beliefs or judgments; in section 4, I discuss Timothy Williamson's ([36], [35]) elaborate deflationist view according to which intuitions are either beliefs or inclinations to believe. In section 5, I argue that rationalist inflationist accounts of intuitions are not plausible because they do not capture all relevant cases. In section 6, I conclude by showing how a non-rationalist inflationist view meets the desiderata for an ontology of intuitions presented in section 2 best.

\section{Desiderata for an Ontology of Intuitions}

Let me present some examples of paradigmatic cases in which philosophers use the term 'intuition'. Any presentation of these cases will be disputable to some extent. In order to avoid begging the question against deviant descriptions, let me introduce a hypothetical philosopher Helen. Helen's apprehension of the cases might not be shared by everyone. However, philosophers in the current methodological debate have described themselves as being in similar situations with respect to the cases below or with respect to other paradigmatic cases. In this sense, Helen is a representative contemporary philosopher.

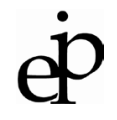


Here are three well-known thought experiments.

\section{Case 1: Gettier Case}

Smith has applied for a job. He has a justified belief that someone else, Jones, will get the job, and he also has a justified belief that Jones has 10 coins in his pocket. Smith therefore justifiably believes that the man who will get the job has 10 coins in his pocket. In fact, Jones does not get the job and Smith himself does. As it happens, Smith unknowingly also has 10 coins in his pocket. His belief that the man who will get the job has 10 coins in his pocket therefore was justified and true. ${ }^{4}$

\section{Case 2: Trolley Case}

A trolley is hurtling down a track towards five people. You are on a bridge under which it will pass, and you can stop it by dropping a heavy weight from the bridge. There is a very fat man standing next to you on the bridge, and the only way to stop the trolley is to push him over the bridge and onto the track, killing him in order to save the five people on the track. Should you push the fat man over the bridge? ${ }^{5}$

\section{Case 3: Mary Case}

'Mary is a brilliant scientist who is, for whatever reason, forced to investigate the world from a black and white room via a black and white television monitor. She specializes in the neurophysiology of vision and acquires, let us suppose, all the physical information there is to obtain about what goes on when we see ripe tomatoes, or the sky, and use terms like 'red', 'blue', and so on. She discovers, for example, just which wavelength combinations from the sky stimulate the retina, and exactly how this produces via the central nervous system the contraction of the vocal cords and expulsion of air from the lungs that results in the uttering of the sentence 'The sky is blue' (...) What will happen when Mary is released from her black and white room or is given a color television monitor? Will she learn anything or not? ${ }^{6}$

Helen has the following reactions to the three cases. Concerning the Gettier Case, she has the intuition that Smith does not have knowledge. Concerning the Trolley Case, she has the intuition that she should not push the fat man over the bridge. Concerning the Mary Case, she has the intuition that Mary will learn something new.

Here are three paradox cases. First, take the following version of the Lottery Paradoxes.

\section{Case 4: Lottery Paradox}

$p: S$ knows that $S$ will not have enough money to go on a safari this year.

$q$ : If $S$ knows that $S$ will not have enough money to go on a safari this year, then $S$ is in a position to know that $S$ will not win a major prize in a lottery this year.

$r: S$ is in not in a position to know that $S$ will not win a major prize in a lottery this year. 
These propositions are jointly inconsistent. From $(p$ and $q)$ it follows that $r$ is false. Equally, from ( $p$ and $r$ ) it follows that $q$ is false, and from ( $q$ and $r$ ) it follows that $p$ is false. In the Lottery Paradox, all three propositions $p, q$, and $r$ considered individually are intuitive to Helen.

Second, here are the three propositions that form the basis of the Paradox of the Heap.

Case 5: Paradox of the Heap

$p$ : A pile of sufficiently many grains is a heap.

$q$ : One single grain cannot make a difference to whether something is a heap or not.

$r$ : A single grain is not a heap.

As in Case 4, the propositions considered individually are intuitive to Helen, but they are jointly inconsistent. Now, suppose Helen has solved the paradox and justifiably believes that $q$ is false. ${ }^{8}$ Nevertheless, it is still intuitive to Helen that $q$, i.e., it is still intuitive to her that if two piles of sand differ just in one single grain, they are either both heaps or neither is a heap.

Third, here is a paradox case discussed in the philosophy of art.

\section{Case 6: Paradox of Emotional Response to Fiction}

$p$ : We cannot feel pity for someone we don't believe exists.

$q$ : If we cannot feel pity for someone we don't believe exists we cannot feel pity for a fictional character.

$r$ : We can feel pity for Anna Karenina. ${ }^{9}$

As in Cases 4 and 5, the propositions are jointly inconsistent, given that Anna Karenina is a fictional character. As in Cases 4 and 5, all propositions are individually intuitive to Helen. Suppose that Helen endorses a theory of quasi-emotion and rejects $r$ on the basis of it. ${ }^{10}$ As in Case 5, it is still intuitive to her that $r$, i.e., it is still intuitive to her that we (i.e., Helen or any other subject) can feel pity for Anna Karenina.

Let me point to some phenomena that can be observed with respect to these cases. As to Case 1, our philosopher Helen has the intuition that a person in the Gettier Case does not have knowledge, but she also believes that a person in the Gettier Case does not have knowledge. The fact that she also believes the proposition that is intuitive to her might lead one to the view that her intuition in this case ought to be identified with her belief. In the contemporary debate over the ontology and epistemic role of intuitions, Gettier Cases have been referred to as paradigmatic cases of intuition driven philosophy. ${ }^{11}$ Taking them to be paradigmatic might incline one to endorse a deflationist view according to which intuitions in general are just beliefs or belief-like states. Such an account seems appealing 
due to its simplicity. However, it is worthwhile to shed light on other cases that have been subject to extensive first-order philosophical debates.

A first phenomenon to be observed with respect to Cases 2 to 6 is that we do not necessarily believe what is intuitive to us. In Case 2, the Trolley Case, Helen has the intuition that she should not push the fat man over the bridge. However, she knows that the numerous Trolley Cases are subject to extensive debates in moral philosophy, and not knowing these cases and debates in much detail, she cannot decide what to believe. She therefore refrains from judging. The adequate description seems to be that she has the intuition but she does not believe that she should not push the fat man over the bridge. Case 4, the Lottery Paradox, is similar to Case 2 insofar as Helen does not know what to believe either. She finds all propositions intuitive, but since they are inconsistent, she refrains from judging. A similar phenomenon can be observed with respect to Cases 3, 5, and 6. Whenever Helen goes through Case 3, the Mary Case, she has the intuition that Mary learns something new when she gets released from her black and white room. However, Helen also firmly believes that physicalism is true, and she believes that the content of her intuition is inconsistent with the truth of physicalism. The adequate description seems to be that Helen has the intuition but she does not believe that Mary learns something new. As I have presented Cases 5 and 6, Helen has solved the paradoxes and believes not- $q$ and not- $r$, respectively. Nevertheless, she has intuitions towards all three propositions $p, q$, and $r$ in both cases. In Case 5, she has the intuition that one single grain cannot make a difference to whether something is a heap or not, but she believes that it can make a difference. In Case 6, she has the intuition that we can feel pity for Anna Karenina, but she does not believe we can. In both cases, Helen is aware of the fact that her belief is inconsistent with her intuitions. (It will later be obvious why we need both Cases 5 and 6.)

Cases 3, 5, and 6 moreover show that intuitions often are resistant to conflicting beliefs. When we think about philosophical problems, we sometimes start out with an intuition that $p$ and then try to support $p$ with a well-founded theory. In paradox cases such as Cases 5 and 6, we begin finding each of a set of contradicting propositions intuitive and search for a theory which, other things being equal, will preserve as many of our intuitions as possible. Even if we come to be convinced of a theory that is inconsistent with one or more of our intuitions, we often keep finding each proposition of the set intuitive. Similarly in Case 3, the Mary Case: even though Helen is convinced that physicalism is true, she keeps having the intuition that $p$ while she believes $p$ to be inconsistent with physicalism. It is worth noticing that in cases like 3,5 and 6 , our intuitions are resistant to conflicting beliefs - or at least more resistant than (philosophical) beliefs usually are. ${ }^{12}$

In Cases 3 to 6 , the fact that Helen has the intuition that $p$ without believing that $p$ is accompanied by a phenomenon concerning rationality. With respect to Case 4 , the 
Lottery Paradox, believing $p, q$, and $r$ altogether would be irrational, because $p, q$ and $r$ form a contradictory set of propositions. However, it does not seem to be irrational to find each of the propositions intuitive, i.e., to have the intuition that $p$, and the intuition that $q$, and the intuition that $r$. Similarly with respect to Cases 3, 5, and 6 . Whereas having a belief that $q$ and a belief that not- $q$ at the same time would seem clearly irrational, finding $q$ intuitive and believing not- $q$ seems at most to be irrational in a nonculpable way. I will call this phenomenon concerning rationality the Rationality Challenge to an ontology of intuitions.

I have shown that Cases 1 to 6 reveal some features that seem to be distinctive of the states we call 'intuitions' in philosophy. I will now suggest desiderata for an ontology of these states. A first and probably uncontroversial desideratum is that an account of intuitions meets our pre-theoretical beliefs about the most central uses of the term 'intuition' in philosophy. An ontology of intuitions should

D1: capture our beliefs about paradigmatic uses of the term 'intuition' in philosophy.

I have suggested that Cases 1 to 6 are paradigmatic cases. In what follows, I will not further question this choice and assume that Cases 1 to 6 pick out paradigmatic phenomena. Corresponding to these phenomena, let me suggest the following further desiderata for an ontology of intuitions. An ontology of intuitions should

D2: allow for cases in which we have an intuition that $p$ but no belief that $\mathrm{p}$,

D3: explain why intuitions sometimes are resistant to conflicting beliefs,

D4: explain why there seems to be no failure of rationality in the case of a set of inconsistent intuitions or an intuition that $p$ and a belief that not- $p$ whereas there would be such a failure in the case of beliefs (the Rationality Challenge).

I do not take these desiderata to provide individually necessary nor jointly sufficient constraints on a correct account of intuitions. However, I think that they provide a useful guide for evaluating an ontology of intuitions: a theory that can account for more or all of the criteria should be favoured over a theory that can account for less of the criteria.

In the following two sections, I discuss two deflationist accounts of intuitions, a simple deflationist and an elaborate deflationist account. 


\section{Simple Deflationism and the Rationality Challenge}

According to a simple deflationism, intuitions are just judgments or beliefs. Simple deflationist views are not popular in the current debate over intuitions in philosophy. ${ }^{13}$ However, understanding why such a view fails will help us to understand why a more elaborate deflationist account of intuitions is popular. The problems the simple deflationist faces with respect to D2 and D3 have been discussed in the literature. ${ }^{14}$ I will therefore address them only briefly and then focus on D4, which philosophers have not paid much attention to. Understanding why D4 constitutes a problem for the simple deflationist will help us to evaluate an elaborate deflationist account in section 4 .

It is obvious that a simple deflationist view cannot meet D2, the desideratum that an account of intuitions should allow for cases in which we have an intuition that $p$ but no belief that $p$. In fact, D2 seems to beg the question against simple deflationism. However, the burden of proof rests on the simple deflationist to explain why there are apparent cases in which we have an intuition that $p$ but no belief that $p$. She could argue that Cases 2 to 6 are not paradigmatic of our use of 'intuition' in philosophy or that they are not relevant for other reasons. But this line of argument seems quite implausible in the face of the important role these cases play in philosophical debates. The Trolley Cases, for instance, have been discussed excessively in moral philosophy, and paradoxes play a central role in contemporary debates about the rationality of belief. We can simply point to the fact that the simple deflationist view would not meet D1, the claim that an ontology of intuitions should treat as true our beliefs about which are paradigmatic uses of the term 'intuition' in philosophy.

Alternatively, the simple deflationist might disagree with the description of the cases and claim that in the Trolley Case (Case 2), Helen actually believes that we should not push the fat man, and in Cases 3 to 6 (the Mary Case and the paradox cases), Helen has contradicting beliefs. The simple deflationist would then have to give an explanation of why Cases 2 to 6 appear to be such that we have an intuition that $p$ but no belief that $p$. I do not know what such an explanation would look like, but even if we grant the simple deflationist this description of the cases, she still owes us an explanation of why the states we call 'intuitions' are often resistant to conflicting beliefs (D3) and why there seems to be no failure of rationality in Cases 3 to 6 (D4). Let us therefore move on to D3.

With respect to D3, the simple deflationist could argue that resistance to conflicting beliefs is not special to the states we call 'intuitions', but is a common psychological phenomenon with respect to belief in general. However, it is up to the simple deflationist to show that there are other cases of resistant belief that are not instances of our use of the word 'intuition' and in which the phenomenon is as obvious as in Cases 3, 5 and 6. In Cases 3, 5, and 6, Helen's intuitions are quite strong, even after having rejected their content and having adopted conflicting beliefs. Even if the simple deflationist can give 
such cases of resistant belief, she would ideally have to give an explanation of why our beliefs are sometimes resistant to conflicting beliefs. At the very least, a theory that can provide such an explanation is to be favoured over a theory that cannot, and as we will see below, some inflationist views can provide such an explanation.

I will now discuss a phenomenon that has not yet received much attention in the current debate (most likely because the Gettier Cases have been in the focus): the fact that there seems to be no failure of rationality in Cases 3 to 6 (D4). I will show that two obvious strategies to deal with $\mathrm{D} 4$ within a simple deflationist view of intuitions are problematic. First, the simple deflationist might identify Helen's intuitions with degrees of belief: in Cases 2 to 6 , she does not fully believe the propositions, she rather believes them to a certain degree only. ${ }^{15}$ The simple deflationist might then go on to argue that a certain distribution of credences makes Helen's beliefs in Cases 3 to 6 rational. Second, the simple deflationist might reject a version of the Conjunction Principle, which is the principle according to which if we are rational, then if we believe a set of propositions, we also believe the conjunction of them. The simple deflationist might hold that whereas believing a conjunction of inconsistent propositions is irrational, believing every proposition individually is not irrational. If the Conjunction Principle (a version of it, that is) does not hold, we have an explanation of why is not irrational to believe all propositions of a paradox. In what follows, I will show that both strategies, identifying intuitions with degrees of belief and rejecting a version of the Conjunction Principle, face serious problems.

Let me show that there are good reasons to reject an account of intuitions in terms of degrees of belief. To begin with, such an account of intuitions does not predict all of our judgments about the cases correctly. According to an account of degrees of belief, mere coherence makes our beliefs rational: a subject $S$ is rational if the degrees of her contradicting beliefs $p$ and not- $p$ add up to 1 on a scale from 0 to 1 . Consider the following two ways of denying full credence in contradicting beliefs:

(i) $S$ fully believes that $p$ (or not-p) and believes to a certain degree that not- $p$ (or that $p$ ).

(ii) $S$ believes to a certain degree that $p$ and believes to a certain degree that not-p.

Take an instance of (i) and an instance of (ii) that are relatively similar with respect to the distribution of degrees of confidence. (i): $S$ believes $p$ with a degree of confidence 1 and believes not-p, say, with a degree of confidence 0.1. In this case, $S$ is not rational. (ii): $S$ believes $p$ with a degree of confidence 0.9 and believes not- $p$ with a degree of confidence 0.1 . Now in this case, $S$ is rational. 
We need Cases 3, 5, and 6 (the Mary Case, the Paradox of the Heap and the Paradox of Emotional Response to Fiction) to be instances of (ii), because we described Helen as rational in these cases. But if an account of intuitions as degrees of belief were true, Cases 3, 5, and 6 would have to be described as instances of (i). This is because in all three cases, our philosopher Helen is fully convinced that not- $p$, but she still has an intuition that $p$. According to an account of intuitions as degrees of belief, she would believe that not- $p$ with a degree of confidence 1 and nevertheless believe to a certain degree that $p$. Hence, she would not be rational. In Cases 3, 5, and 6 as described above, however, she seems to be rational.

Moreover, this account cannot explain why we do not seem irrational in some cases of conflicting beliefs, whereas we seem clearly irrational in others. For instance, we do not seem to be irrational in cases like the Lottery Paradox (Case 4), in which we - according to the simple deflationist - believe a set of inconsistent propositions. The explanation a proponent of intuitions as degrees of belief gives is that the distribution of credences is coherent. However, take any ordinary set of inconsistent propositions belief in which would seem obviously irrational. An account of intuitions as degrees of belief does not provide an explanation of why our credences in paradox cases are distributed such that they are coherent, whereas they are not distributed in such a way in the case of any other ordinary inconsistent set of beliefs.

Let me now discuss a second strategy the simple deflationist can take in order to meet the Rationality Challenge (D4). This second strategy is to reject a version of the Conjunction Principle. Here is the most general version of the principle:

Conjunction Principle: If $S$ is rational, then if $S$ believes $p$ and $S$ believes $q$, then $S$ believes ( $p$ and $q$ ).

The Conjunction Principle implies that belief in some contradictions is rational paradoxes being paradigmatic cases. However, it is widely accepted that any theory of rational belief is in need of a principle prohibiting belief in a contradiction ${ }^{16}$ :

No Contradiction Principle: If $S$ is rational, then $S$ does not believe ( $p$ and not-p).

Obviously, the No Contradiction Principle is in conflict with the Conjunction Principle, so we have to abandon one of them. Rejecting the No Contradiction Principle is a possible way to go, but it is certainly the least popular way. ${ }^{17}$ In the literature on rational belief, some philosophers discard the Conjunction Principle as an attempt to provide an explanation of why we do not seem irrational in paradox cases. ${ }^{18}$ This strategy allows us to believe all propositions of a paradox individually without believing the conjunction of them. Whereas believing the conjunction is considered irrational, believing the conjuncts 
individually is not considered as irrational.

The simple deflationist could make use of this strategy in order to explain why we do not seem irrational in Cases 3 to 6 . However, she does not need to reject a principle as general as the Conjunction Principle. It seems that a subject $S$ can, without being irrational, hold beliefs that are implicitly contradictory, i.e., beliefs that imply $p$ and not- $p$ without $S$ knowing or being aware of it. We often hold inconsistent beliefs either for a lack of knowledge or a lack of reflection, and it is at least controversial whether we are irrational in these cases. The cases under consideration, however, are cases of conscious belief in which we are aware of the inconsistency in our set of beliefs. We are perfectly aware of all three propositions of the paradox cases and the fact that they are inconsistent. This is obvious from the fact that we consider Cases 4, 5 and 6 as paradoxical. The same is true for Case 3, the Mary Case: the intuition, the belief, and the fact that they are inconsistent are conscious to our philosopher Helen. Hence, all we need is a principle that prohibits conscious belief in a conscious contradiction ( $p$ and not- $p$ ). Here is a modification of both principles:

Conjunction Principle*: If $S$ is rational, then if $S$ consciously believes $p$ and $S$ consciously believes $q$, then $S$ consciously believes ( $p$ and $q$ ).

No Contradiction Principle*: If $S$ is rational, then $S$ does not consciously believe ( $p$ and not- $p$ ).

Suppose that the strategy the simple deflationist would want to pursue is to reject the Conjunction Principle* on the evidence of paradoxes.

I do not think that this is a reasonable strategy. It goes beyond the scope of the paper to argue conclusively against it, but I will make some considerations that strike me convincing. Let me go back to the general version of the principle, to the Conjunction Principle. Rejecting the Conjunction Principle commits one to the claim that there is a difference between being in a state of having contradictory beliefs and being in a state of believing a contradiction, so that one could individually believe $p$ and $q$ without thereby consciously believing the conjunction $(p$ and $q)$. This is a controversial claim. Simon Evnine [9], for instance, suggests that

(...) in normal circumstances, being in a state of believing a conjunction simply is being in a state of believing its conjuncts. There is no state of believing $\mathrm{A}$ and $\mathrm{B}$, distinct from the state of believing $\mathrm{A}$ and believing B. ${ }^{19}$

Evnine thinks that in normal circumstances, it is presupposed by our practice of attributing conjunctive beliefs that there is only one state. For instance, when we 
summarize a person's position, we do this by attributing a conjunctive belief. We do not require evidence that some psychological process has occurred in which all the individual beliefs were conjoined to one single belief. In a second step, Evnine argues that if it is not even possible that we believe the conjuncts without believing the conjunction, then the normative claim, the Conjunction Principle, is true as well: If $S$ is rational, then if $S$ believes $p$ and $S$ believes $q$, then $S$ believes $(p$ and $q){ }^{20}$

This argument should especially apply to cases of a small number of conscious beliefs where we are also aware of the inferential relations between these beliefs - cases such as paradoxes and thought experiments. For these rather simple cases at least, Evnine's claim seems quite plausible. Furthermore, we can argue against the simple deflationist that if it is not even possible not to believe the conjunction while believing the conjuncts, then the normative claim, the Conjunction Principle*, is true as well: if $S$ is rational, then if $S$ consciously believes $p$ and $S$ consciously believes $q$, then $S$ consciously believes ( $p$ and $q)$.

I have argued that two prima facie plausible strategies to defend a simple deflationist account of intuitions against the rationality challenge (D4) are problematic. Both strategies do not provide a satisfying explanation of why we are not irrational in Cases 3 to 6. The deflationists in the current debate over the ontology of intuitions seem to acknowledge that a more elaborate deflationism is required. In the following section, I present and discuss Williamson's account, according to which an intuition is either a belief or an inclination to believe. I show that a disambiguation of the term 'inclination to believe' allows for two different accounts. The account that fits in naturally with a deflationist view fails to meet D4 for reasons similar to the ones discussed with respect to simple deflationism. Whereas the second account meets D4, I show in sections 4 and 5 that some inflationist accounts have a substantial advantage over it: they provide an explanation of why intuitions sometimes are resistant to conflicting beliefs, i.e., they meet D3.

\section{An Elaborate Deflationist Account}

According to Williamson ([36], [35]), to have the intuition that $p$ is either to believe that $p$ or to be merely consciously inclined to judge or believe that $p .^{21}$ This allows Williamson to accommodate Cases 1 to 6: in Case 1, the Gettier Case, our philosopher Helen believes that the person has no knowledge; in Cases 2 to 6, she is merely consciously inclined to believe the respective propositions. Williamson's deflationist view of intuitions not only allows for cases in which we have an intuition but no belief (D2), it also provides an explanation of why we do not seem to be irrational in Cases 3 to 6 (D4). The explanation it provides is that in these cases, we are merely consciously inclined to believe that $p$, which means we are not committed to the truth of the content 
of our conscious inclinations to believe. If $S$ believes that $p, S$ is committed to the truth of $p$, but if $S$ is merely consciously inclined to believe that $p, S$ is not committed to the truth of $p$.

In the way in which I am committed to the propositions that I believe, I am not committed to the propositions that I am merely inclined to believe; I am merely inclined to commit myself to them in that way. ${ }^{22}$

At first sight, this account provides a neat explanation of why there seems to be no failure of rationality in cases 3 to 6 . Because there is no commitment to the truth involved in inclinations to believe, they do not obey any version of the No Contradiction Principle. In Case 4, the Lottery Paradox, we have conscious inclinations to believe all three propositions of the inconsistent set of propositions. Since we are not committed to the truth of the propositions, the inconsistency of the propositions does not pose a problem. In Cases 3, 5 and 6, we have a conscious inclination to believe that $p$ and a belief that not- $p$. The explanation of why we do not seem to be irrational in these cases is again that we are not committed to the truth of the content of our conscious inclination to believe that $p$.

The following observations cast doubt on the impression that the explanation of why there seems to be no failure of rationality applies to Cases 3, 5 and 6. Recall that in these cases, we have a firm belief that not-p. Wouldn't we expect it to be irrational to be consciously inclined to believe that $p$, given that we consciously believe that $p$ is inconsistent with our firm belief? Intuitively, we are not even consciously inclined to believe that $p$ in these cases.

There is at least a prima facie difference between cases where we have an intuition that $p$ and a firm belief that not-p on the one hand (Cases 3,5 and 6) and cases where we have an intuition that $p$ without a firm belief that not- $p$ on the other hand (Case 4). We should expect it to seem at least more irrational to be consciously inclined to believe $p$ in the case in which we have the firm belief that not- $p$ than in the case in which we only have a contradicting conscious inclination to believe not- $p$. After all, we are committed to the truth of our firm belief in Cases 3, 5, and 6, whereas we are not committed to the truth of our inconsistent conscious inclinations in Case 4. However, all cases are similar with respect to rationality: we seem not irrational in Cases 3,5 and 6 to the same extent as in Case 4.

Are Cases 3, 5 and 6 really such that we are consciously inclined to believe the content that contradicts our firm belief? There are not many arguments to be found in the literature as to whether in these cases, our intuitions are to be identified with conscious inclinations to believe or not. Williamson makes the following introspective claim. 
I can feel such an inclination even if it is quite stably overridden, and I am not in the least danger of giving way to temptation (just as one can feel the inclination to kick someone without being in the least danger of giving way). ${ }^{23}$

In contrast, some authors think that these cases are such that we have an intuition that $p$ without a conscious inclination to believe that $p$. Earlenbaugh and Molyneux [8] have the following intuition.

There at least appear to be cases where one has an intuition without an accompanying inclination to believe. It seems coherent, that is, to claim

\section{(...) I have an intuition that P but I am not inclined to believe it. ${ }^{24}$}

As an example of such a case, they mention the Naive Comprehension Axiom, which is intuitive to us although we have a firm belief that it is not true. This case is parallel to our Cases 3, 5, and 6 .

But is there more to say about whether there are cases where one has an intuition that $p$ without an inclination to believe that $p$ than introspections and intuitions? Let me disambiguate the term 'inclination to believe' and introduce a distinction between 'doxastic inclinations to believe' and 'merely psychological inclinations to believe'. Doxastic inclinations to believe work in certain respects like guesses. If $S$ guesses that $q$, $S$ is not committed to the truth of $q$. However, if $S$ firmly believes not- $q$ and is rational, she does not guess that $q$. Her guess that $q$ commits her to stop guessing that $q$ as soon as she firmly believes not- $q$. Similarly, if $S$ firmly believes not- $q$ and is rational, she is not inclined to believe that $q .{ }^{25}$ Doxastic inclinations to believe are derivatives of belief in the sense that they involve some kind of rational commitment, i.e., they inherit some rationality principles from belief. They certainly do not inherit the No Contradiction Principle*, because the fact that we do not violate this principle when we have contradictory conscious inclinations to believe is exactly the work inclinations to believe do as opposed to beliefs. However, doxastic inclinations to believe are likely to inherit Closure under Consciously Known Entailment. This principle is not affected by the work inclinations to believe do as opposed to beliefs. Suppose that conscious belief is closed under consciously known entailment:

Closure under Consciously Known Entailment (for conscious belief): If $S$ is rational, then if $S$ consciously believes that $p$ and consciously believes that $q$ is entailed by $p$, and considers whether $q$, then $S$ consciously believes that $q$.

For instance, suppose that Emma consciously believes that if the cat is in the kitchen, it is not in the garden. If Emma also consciously believes that the cat is in the kitchen, then if 
she is rational, Emma consciously believes that it is not in the garden. Now suppose that Emma wonders where the cat is and for some reason comes to be consciously inclined to believe that the cat is in the kitchen, but she does not believe it (say, because her evidence is rather poor). Suppose further that Emma now considers whether the cat is in the garden. Then if she is rational, she will be consciously inclined to believe that the cat is not in the garden. In other words, it seems plausible that conscious doxastic inclination to believe is closed under consciously known entailment:

Closure under Consciously Known Entailment (for conscious doxastic inclination to believe): If $S$ is rational, then if $S$ is consciously doxastically inclined to believe that $p$ and consciously knows that $q$ is entailed by $p$, and considers whether $q$, then $S$ is consciously doxastically inclined to believe that $q$.

The simple case given above makes it plausible that Closure under Consciously Known Entailment holds not only for conscious beliefs but for conscious doxastic inclinations to believe, too.

I will now show that a doxastic inclination to believe that $p$ is neither sufficient nor necessary for an intuition that $p$ in the relevant cases. Let us first have a look at Case 4 again. Suppose we are doxastically inclined to believe the contents of our intuitions in the Lottery Paradox. Here are the propositions again.

$p$ : $S$ knows that $S$ will not have enough money to go on a safari this year.

$q$ : If $S$ knows that $S$ will not have enough money to go on a safari this year, then $S$ is in a position to know that $S$ will not win a major prize in a lottery this year.

$r: S$ is in not in a position to know that $S$ will not win a major prize in a lottery this year.

It is plausible to suppose that $S$, who is a rational subject and understands the paradox, consciously knows that, for instance, ( $p$ and $r$ ) entails not- $q$. Then the following is the case: if $S$ is rational, then if $S$ is doxastically inclined to believe that $p$ and is doxastically inclined to believe that $r$, then $S$ is also doxastically inclined to believe that not-q. $S$ then has two contradicting doxastic inclinations to believe that $q$ and not- $q$, i.e., the doxastic inclination to believe that if $S$ knows that $S$ will not have enough money to go on a safari this year, then $S$ is in a position to know that $S$ will not win a major prize in a lottery this year, and the doxastic inclination to believe that it is not the case that if $S$ knows that $S$ will not have enough money to go on a safari this year, then $S$ is in a position to know that $S$ will not win a major prize in a lottery this year. 
This seems to be a plausible description of the case. However, whereas $S$ has the intuition that $q, S$ obviously does not have the intuition that not- $q$. That is, $S$ has an intuition with the content that if $S$ knows that $S$ will not have enough money to go on a safari this year, then $S$ is in a position to know that $S$ will not win a major prize in a lottery this year, but $S$ does not have an intuition with the content that it is not the case that if $S$ knows that $S$ will not have enough money to go on a safari this year, then $S$ is in a position to know that $S$ will not win a major prize in a lottery this year. If we accept that doxastic inclinations to believe obey Closure under Consciously Known Entailment, this shows that a doxastic inclination to believe is not sufficient for an intuition.

In order to show that a doxastic inclination to believe is not necessary for an intuition in the relevant cases either, let us have a look at cases in which $S$ has an intuition that $q$ and a firm belief that not- $q$ (Cases 3, 5 and 6). In these cases, $S$ does not believe that $q$. Furthermore, $S$ does not even seem to be doxastically inclined to believe what is entailed by the content of her intuition that $q$. Take Case 3. If $S$ has the firm belief that physicalism is true and the intuition that Mary learns something, $S$ does not have the intuition that physicalism is false, and $S$ does not even have the doxastic inclination to believe that physicalism is false. After all, $S$ has a firm belief that physicalism is true. According to an account that does not reduce intuitions to doxastic inclinations to believe, this is because $S$ does not have the doxastic inclination to believe that $S$ learns something, but merely an intuition, and intuitions do not obey Closure under Consciously Known Entailment. If this is the correct description of the cases, it shows that a doxastic inclination to believe is not necessary for an intuition.

Which notion of inclination to believe does Williamson employ, 'doxastic inclination to believe' or 'merely psychological inclination to believe'? Given Williamson's account of belief and given that he defends a reductive account of intuitions according to which intuitions are either beliefs or inclinations to believe ${ }^{26}$, it seems more in his spirit to endorse an account of doxastic inclinations to believe. This, however, would mean that Williamson's account does not meet D4: it does not explain why we are not irrational in cases where we firmly believe that not- $p$ and have an intuition that $p$. Alternatively, Williamson's view could be that intuitions are either beliefs or merely psychological inclinations to believe. In order to defend such a view of intuitions, one would have to say more about two things: in what sense such an account of intuitions would be a reductive account and what merely psychological intuitions are. In any case, Williamson's account does not provide an explanation of why intuitions are often resistant to conflicting beliefs and hence does not meet D3.

In the following two sections, I present two kinds of inflationist accounts of intuition rationalist accounts and a non-rationalist account - that do not only meet D2 and D4, but also D3. However, rationalist inflationist accounts do not meet D1. 


\section{Rationalist Inflationist Accounts}

George Bealer thinks that the fact that intuitions are more resistant to conflicting evidence and other influences reveals a distinctive feature of intuitions. ${ }^{27}$

(...) nearly any proposition about which you have beliefs, authority, cajoling, intimidation, and so forth can, fairly readily, insinuate at least some doubt and thereby diminish to some extent, perhaps only briefly, the strength of your belief. But seldom, if ever, do these things so readily diminish the strength of your intuitions. Just try to diminish readily your intuition of the naive comprehension axiom or your intuition that your favourite Gettier example could occur. Although there is disagreement about the degree of plasticity of intuitions (...) it is clear that, as a family, they are inherently more resistant to such influences than are the associated beliefs. ${ }^{28}$

Intuitions share the property of being more resistant with perceptual seemings:

(...) I have an intuition - it still seems to me - that the naïve comprehension axiom of set theory is true; this is so despite the fact that I do not believe that it is true (because I know of the set-theoretical paradoxes). There is a rather similar phenomenon in sense perception. In the Mueller-Lyer illusion, it still seems to me that one of the two arrows is longer than the other; this is so despite the fact that I do not believe that one of the two arrows is longer (because I have measured them). In each case, the seeming persists in spite of the countervailing belief. ${ }^{29}$

According to Bealer's inflationist view, the fact that intuitions are more resistant to conflicting beliefs shows that intuitions are not beliefs but instead a sui generis propositional attitude:

When you have an intuition that A, it seems to you that A. Here 'seems' is understood, not in its use as a cautionary or 'hedging' term, but in its use as a term for a genuine kind of conscious episode. For example, when you first consider one of de Morgan's laws, often it neither seems true nor seems false; after a moment's reflection, however, something happens: it now just seems true. The view I will defend is that intuition (this type of seeming) is a sui generis, irreducible, natural (...) propositional attitude that occurs episodically. ${ }^{30}$ 
By postulating a sui generis propositional attitude, Bealer's account of intuitions is able to meet desiderata D2, D3, and D4. However, Bealer's account does not meet D1, according to which an account of intuitions should capture our beliefs about which cases are paradigmatic uses of the term 'intuition' in philosophy. According to Bealer, philosophically relevant intuitions - for instance intuitions we have when we engage in thought experiments and think about paradoxes - are all rational intuitions. Although they are fallible, rational intuitions can provide a priori knowledge and have to be distinguished from physical intuitions. When we have a rational intuition, the content of the intuition is presented as necessary, and the source of rational intuitions is mere understanding. ${ }^{31}$ Physical intuitions stem from the experience we have of the contingent physical world, and their content is not presented as necessary. ${ }^{32}$ An example of a physical intuition Bealer mentions is that it seems to us that when a house is undermined, it will fall. Further examples are the intuitions we have when we engage in scientific thought experiments like Schroedinger's case of the cat in the box or Galileo's case on velocity. ${ }^{33}$ Although physical intuitions may well be a kind of intuition, only rational intuitions are the ones at issue in philosophy. ${ }^{34}$

Let us have a look at another rationalist account of intuitions. It is essential to Ernest Sosa's competence model of intuitions that rational intuitions have modally strong content and are gained through understanding only, and that they are reliable due to a competence.

An intellectual seeming is intuitive when it is an attraction to assent triggered simply by considering a proposition consciously with understanding. (...) $S$ rationally intuits that $p$ if and only if S's intuitive attraction to assent to $p$ is explained by a competence (an epistemic ability or virtue) on the part of $S$ to discriminate, among contents that he understands well enough, the true from the false, in some subfield of the modally strong (the necessarily true or necessarily false), with no reliance on introspection, perception, memory, testimony, or inference (nor further reliance, anyhow, than any required for so much as understanding the given proposition). ${ }^{35}$

Sosa distinguishes animal intuitions from rational intuitions. Whereas the latter can provide a priori knowledge, the former cannot. However, animal intuitions might derive from a competence as well, as for instance the competence of taking experience at face value. Like Bealer, Sosa thinks that only rational intuitions are relevant to our philosophical practice.

Let me say why restricting our considerations to rational intuitions is not a good strategy and why accounts that do so do not meet D1. Compare Cases 5 and 6, the Paradox of the Heap and the Paradox of Emotional Response to Fiction. Whereas the propositions in Case 5 are plausibly known a priori, the propositions in Case 6 clearly are contingent claims that cannot be known a priori. Nevertheless, we can observe the same phenomena 
in both cases: the intuitions are more resistant to conflicting beliefs and it does not seem irrational to have an inconsistent set of intuitions. Moreover, the Paradox of Emotional Response to Fiction is certainly relevant to philosophy. Since its introduction by Colin Radford [23], it has played a central role in the philosophy of art. ${ }^{36}$ Second, it is controversial whether intuitions gained through thought experiments provide a priori knowledge. It is a consequence of Williamson's account of thought experiments that intuitions are judgments of ordinary counterfactuals. As such, they have contingent contents that can only be known a posteriori. Ichikawa and Jarvis [15] take this consequence as a reason to reject Williamson's analysis of thought experiments, because the standard view has it that intuitions like the Gettier intuition can be known a priori. However, Williamson rejects the idea that there is a clear-cut a priori-a posteriori distinction for independent reasons. ${ }^{37}$ A theory of intuitions that can allow for any account of thought experiments therefore is clearly preferable to a theory that is restricted to rational intuitions.

In order to meet D1, we should be looking for an explanation of the phenomena observed in Cases 2 to 6 that covers intuitions independent of whether they can provide a priori knowledge or not. A rationalist inflationist account obviously cannot provide this. Let us finally have a look at a non-rationalist inflationist account of intuitions.

\section{Intuitions as Non-Doxastic Appearance States}

In a short paper titled 'Seemings', William Tolhurst [31] gives a very dense presentation of his account of 'what it is for things to seem to be a certain way' ${ }^{38}$. According to Tolhurst, seeming states are very much like beliefs in that they are intentional states with a mind-to-world direction of fit (other than desires, wishes, etc.), but they are an extra kind of mental state.

Tolhurst [31] thinks that besides seemings that incline us to believe their content, there are appearance states that do not incline us to believe their content. He introduces the term 'appearance' to cover cases where it appears to us that something is the case regardless of whether this inclines us to believe that things are as they appear. He uses the term 'seeming' for appearances that incline us to believe the content and the term 'mere appearance' for those that do not incline us to believe the content. ${ }^{39}$ Tolhurst's 'appearances' are meant to have all kinds of contents. Here is an example of a mere sensory appearance, where something appears to $S$ to be $p$ and $S$ is not inclined to believe that $p$ because $S$ knows that not- $p$ :

Usually an object's looking red inclines one to believe it is red. But this inclination may not arise if one knows it is really a white object under red light. Visual appearances of red paper under normal light can be 
phenomenologically indistinguishable from visual experiences of white paper under red light. In both cases one is appeared to redly. ${ }^{40}$

I will not defend an account of intuitions as a kind of appearances in much detail, but I will show that it meets D1, D2, D3, and D4. It offers an explanation as to why we sometimes do not believe the content of our intuitions (D2), why intuitions are more resistant to conflicting beliefs (D3), why it does not seem to be irrational when we have an inconsistent set of intuitions or an intuition that $p$ and a belief that not- $p$ at the same time (D4), and it also covers all cases presented in section 2 (D1).

Here is why we do not always believe the content of our intuitions (D2). As appearances, intuitions dispose us to believe or to be doxastically inclined to believe their content. They are often but not necessarily accompanied by a belief or a doxastic inclination to believe.

All appearances dispose the subject to believe the content of the seeming. This is not to say that they all provide occurrent motivation, e.g., a felt inclination, to believe; but that they create conditions favourable for believing. This disposition, like other dispositions, is only activated under appropriate circumstances. Things that are brittle have a disposition to crack and shatter: under some circumstances they crack, under more extreme conditions they shatter, but often neither happens because these conditions do not obtain. Likewise, under appropriate circumstances appearances generate beliefs and felt inclinations to believe. When an appearance it decisively defeated or passes unnoticed, the conditions appropriate for the activation of the disposition do not obtain and it may not provide actual psychological support for believing. ${ }^{41}$

Dominic Gregory [13] gives a similar account of the relation between appearances and beliefs:

There are especially intimate links between sensory appearances and many of our beliefs about the outside world. Indeed, the links are so intimate that some philosophers have identified sensory appearances with beliefs, or with the acquisition of beliefs. That identification is too strong - the appearances persist when weÕve not got any inclination to trust them but there is something right about it: part of what it is for sensory appearances to be 'appearances' is that they can be accurate or inaccurate in just the way that beliefs can be. ${ }^{42}$

Appearances are in general more persistent than beliefs, although it might depend on the person's individual psychology whether she keeps having a particular appearance or not. Some person's appearance state might disappear when she changes her beliefs, but another person's might not. There is an explanation for this variation, which is that 
appearances are non-doxastic. As Sosa puts it with respect to sensory experiences:

Since they are only passively received, they cannot manifest obedience to anything, including rational norms, whether epistemic or otherwise. ${ }^{43}$

This is why intuitions are often resistant to conflicting beliefs (D3). The fact that intuitions and other appearances are non-doxastic states explains furthermore why it is not irrational to have an intuition that $p$ and a belief that not- $p$ at the same time (D4).

However, intuitions and other appearances have assertoric force which they share with beliefs and other appearances, and which makes them different from states like wondering, assuming, supposing, and imagining. When we are in an occurrent state of an appearance, the content is presented to us as true of the actual world. ${ }^{44}$ As a consequence, appearances dispose us to form a doxastic attitude towards their content. What are the conditions such that we believe or are doxastically inclined to believe the content of our intuition? Let me again go through the cases introduced in section 2 .

In the Gettier Case (Case 1), the conditions are such that we are not only doxastically inclined to believe, but also believe that the person does not have knowledge. This is because we neither have a contradicting belief nor a contradicting doxastic inclination to believe in this case.

In Cases 2 to 6, the conditions are such that we are at most doxastically inclined to believe the content of our intuition. In the Trolley Case (Case 2), I have no belief or doxastic inclination to believe that contradicts my intuition. Still, I do not believe that I should not push the fat man, because I know that what is the right thing to do in the Trolley Cases is a difficult question, and I would have to think a lot more about the matter in order to form a belief. I might not even be doxastically inclined to believe and instead simply withhold any doxastic attitude in this case.

In the Lottery Paradox (Case 4), we have intuitions towards a set of inconsistent propositions. Since the propositions are inconsistent, the No Contradiction Principle* prevents us from fully believing them. However, nothing prevents us from being doxastically inclined to believe all propositions.

The Mary Case, the Paradox of the Heap and the Paradox of Emotional Response to Fiction (Cases 3, 5 and 6) are such that we do not have any doxastic attitude towards the content of our intuitions. The reason is that we have a firm contradicting belief, so that a belief or a doxastic inclination to believe with the content of the intuition does not occur.

Besides doxastic inclinations to believe and beliefs, there might be several other defeaters that prevent us from believing that $p$. In the Trolley Case, for instance, Helen simply does 
not know what to believe, because she knows that the issue is hard to settle. Hence, a lack of confidence in our judgment in a certain area or our knowledge that we have not fully understood a complex matter might defeat our belief in $p$. Such defeaters might even prevent us from being doxastically inclined to believe. The relevant conditional for intuitions as dispositions to believe will look like this (suppose that having a belief that $p$ entails having a doxastic inclination to believe $p$, but having a doxastic inclination to believe does not entail having a belief that $p$ ).

If $S$ has no firm belief not- $p$ (and no other defeaters), $S$ will be doxastically inclined to believe $p$, and if $S$ has no firm belief and no doxastic inclination to believe that not- $p$ (and no other defeaters), $S$ will believe that $p$.

I have shown that an account of intuitions as non-doxastic appearance states meets all desiderata D1, D2, D3, and D4: it covers the paradigmatic cases (D1), it allows for cases where we have an intuition that $p$ and no belief that $p$ (D2), it explains why some of our intuitions are persistent to conflicting beliefs (D3), and it explains why there seems to be no failure of rationality in the case of a set of inconsistent intuitions or an intuition that $p$ and a belief that not- $p$ (D4). It moreover explains our talk of 'intuitive judgments' or 'intuitive beliefs': these judgements or beliefs are based on intuitions as appearances. The account of intuitions as non-doxastic appearances is a non-rationalist inflationist account of intuitions according to which intuitions are an extra kind of mental state. However, the most important claim seems not to be that intuitions are an extra mental state, but rather that they share less features with belief (as characterized in this paper) than doxastic inclinations to believe.

\section{References}

[1] Allen, R. T. The reality of responses to fiction. British Journal of Aesthetics 26.1 (1986), 64-68.

[2] Bealer, G. The incoherence of empiricsm. In Naturalism: A Critical Appraisal, S. Wagner and R. Warner, Eds. University of Notre Dame Press, Notre Dame, 1993 1993.

[3] Bealer, G. 'a priori' knowledge and the scope of philosophy. Philosophical Studies: An International Journal for Philosophy in the Analytic Tradition 81, 2/3 (1996), 121-142.

[4] Bealer, G. Intuition and the autonomy of philosophy. In Rethinking Intuition. The Psychology of Intuition and Its Role in Philosophical Inquiry, M. R. DePaul and W. Ramsey, Eds. Rowman and Littlefield Publishers, Inc., Lanham, 1998, pp. 201-239. 
[5] Cherniak, C. Minimal Rationality. MIT Press, Cambridge, MA, 1086.

[6] Christensen, D. Putting Logic in its Place. Oxford University Press, New York, 2004.

[7] Deutsch, M. Experimental philosophy and the theory of reference. Mind and Language 24, 4 (2009), 445-466.

[8] Earlenbaugh, J., and Molyneux, B. Intuitions are inclinations to believe. Philosophical Studies (2009).

[9] Evnine, S. J. Believing conjunctions. Synthese 118 (1999), 201-227.

[10] Foley, R. Working Without a Net: A Study of Egocentric Epistemology. Oxford University Press, New York, 1993.

[11] Gettier, E. L. Is justified true belief knowledge? Analysis 23, 121-123 (1963).

[12] Gigerenzer, G. Gut Feelings: The Intelligence of the Unconscious. Viking Adult, 2007.

[13] Gregory, D. Conceivability and apparent possibility.

[14] Hawthorne, J. Knowledge and Lotteries. Oxford University Press, New York, 2004.

[15] Ichikawa, J., and Jarvis, B. Thought-experiment intuitions and truth in fiction. Philosophical Studies 142, 2 (2007), 221-246.

[16] Jackson, F. Epiphenomenal qualia. Philosophical Quarterly 32, 127 (1982), $127-$ 136.

[17] Jackson, F. From Metaphysics to Ethics. Oxford University Press, 1997.

[18] Kornblith, H. The unattainability of coherence. In The Current State of the Coherence Theory, J. Bender, Ed. Kluwer, Dordrecht, 1989.

[19] Kyburg, H. Conjunctivitis. In Induction, Acceptance, and Rational Belief, M. Swain, Ed. Reidel, Dordrecht, 1970.

[20] Lewis, D. Philosophical Papers (Volume 1). Oxford University Press, Oxford, 1983, ch. Postscript to "Mad Pain and Martian Pain".

[21] Priest, G. Contradiction, belief and rationality. In Proceedings of the Aristotelian 
Society (1985/6), no. 86, pp. 99-116.

[22] Pust, J. Intuitions as Evidence. Garland Publishing, New York/London, 2000.

[23] Radford, C. How can we be moved by the fate of anna karenina? In Proceedings of the Aristotelian Society, Supplemental Vol. (1975), no. 49, pp. 67-80.

[24] Schroeder, M. What does it take to 'have' a reason?

[25] Sorensen, R. Thought Experiments. Oxford University Press, New York, 1992.

[26] Sosa, E. Minimal intuition. In Rethinking Intuition. The Psychology of Intuition and Its Role in Philosophical Inquiry, M. R. DePaul and W. Ramsey, Eds. Rowman and Littlefield Publishers, Inc., Lanham, 1998, pp. 257-269.

[27] Sosa, E. A Virtue Epistemology. Oxford University Press, Oxford, 2007.

[28] Stalnaker, R. Inquiry. MIT Press, Cambridge, MA, 1984.

[29] Sturgeon, S. Reason and the grain of belief. Noûs 42, 1 (2008), 139-165.

[30] Thomson, J. J. Killing, letting die, and the trolley problem. The Monist (1976), 204-217.

[31] Tolhurst, W. Seemings. American Philosophical Quarterly 35 (1998), 293-302.

[32] von Inwagen, P. Materialism and the psychological-continuity account of personal identity. In Philosophical Perspectives, J. Tomberlin, Ed., vol. 11. Blackwell Publishers, 1997.

[33] Walton, K. Fearing fictions. Journal of Philosophy 75.1 (1978), 5-27.

[34] Williamson, T. Vagueness. Routledge, London, 1994.

[35] Williamson, T. The Philosophy of Philosophy. Oxford University Press, 2007.

[36] Williamson, T. W. Philosophical 'intuitions' and scepticism about judgement. Dialectica 58, 1 (2004), 109-153.

\footnotetext{
${ }^{1}$ E.g., Gigerenzer [12].

${ }^{2}$ Gettier [11].
} 
${ }^{3}$ Jackson [16]. Most philosophers think that this is not a genuine counterexample to physicalism, including Jackson [17].

${ }^{4}$ Gettier [11].

5 Thomson [30].

${ }^{6}$ Jackson [16, p. 130].

${ }^{7}$ Hawthorne [14, p. 2].

${ }^{8}$ See, e.g., Williamson [34].

${ }^{9}$ See Radford [23].

${ }^{10}$ See, e.g., Walton [33].

${ }^{11}$ See, e.g., Williamson [35].

12 This phenomenon has been discussed in the literature (e.g., Bealer [4], Pust [22]), see section 5.

${ }^{13}$ Previous to the current methodological debate, a simple deflationist view has been held by philosophers such as van Inwagen [32] and Lewis [20].

${ }^{14}$ E.g., Bealer [4].

${ }^{15}$ This view is in line with what Sturgeon [29] calls the Fine View of rational belief.

${ }^{16}$ Evnine [9, p. 202].

${ }^{17}$ For a rejection of the No Contradiction Principle, see Priest [21].

${ }^{18}$ Kyburg [19], Cherniak [5], Kornblith [18], Foley [10], and more recently Christensen [6] and Sturgeon [29].

${ }^{19}$ Evnine [9, p. 215]. See also Stalnaker [28].

${ }^{20}$ Evnine [9, pp. 214f].

${ }^{21}$ Earlenbaugh and Molyneux [8] defend an account of intuitions according to which all intuitions are inclinations to believe.

${ }^{22}$ Williamson [36, p. 128].

${ }^{23}$ Williamson [35, p. 217].

${ }^{24}$ Williamson [35, p. 217]. 
${ }^{25}$ There are, of course, differences between doxastic inclinations to believe and guesses. Whereas we can have contradicting doxastic inclinations to believe, we cannot guess that $p$ and that not- $p$. Hence, guesses seem to obey the No Contradiction Principle.

${ }^{26}$ See, e.g., Williamson [35, p. 216].

${ }^{27}$ For the claim that intuitions cannot be beliefs see Bealer ([4, p. 208], [3, p. 6]), Sosa [26, pp. 258f], Pust [22, pp. 32f].

${ }^{28}$ Bealer [4, p. 208].

${ }^{29}$ Bealer [4, p. 208].

${ }^{30}$ Bealer [4, p. 207].

${ }^{31}$ Pust [22] endorses a version of Bealer's view of rational intuitions. However, he thinks that considering the fact that we can have the intuition that $p$ and at the same time the belief that not- $p$, the necessity of the content does not have to be part of the experience of the occurrent state. Propositions about hypothetical cases, for example, sometimes do not seem initially necessarily true to us. We only have to come to the seeming that necessarily $p$ when we consider whether $p$ is necessarily true.

${ }^{32}$ Bealer [4, pp. 207ff].

${ }^{33}$ See Sorensen [25] for thought experiments in the sciences.

${ }^{34}$ Bealer [2, p. 105], Pust [22, pp. 35f]. According to Bealer, the fact that a proposition can be

known a posteriori rules out the possibility of having a (rational) intuition towards it: Presumably, by suitably modifying the brain we could cause a subject to acquire the sort of spontaneous inclination (...) We could, for example, cause someone to have a spontaneous inclination to believe that gold has atomic number 79. (. . ) Likewise for other a posteriori necessities. But the person still would not be able to intuit these necessities, for in that case they would be a priori, not a posteriori, as everyone takes them to be.' [4, p. 209].

${ }^{35}$ Sosa [27, pp. 60f].

${ }^{36}$ E.g., Allen [1], Walton [33].

${ }^{37}$ See Williamson [35].

${ }^{38}$ Tolhurst [31, p. 293].

${ }^{39}$ Tolhurst [31, pp. 295f].

${ }^{40}$ Tolhurst [31, p. 295]. Sensory appearances might have a special phenomenology that other appearances do not have.

${ }^{41}$ Tolhurst [31, p. 296]. 
${ }^{42}$ Gregory [13, p. 321]. Gregory takes sensory and memory appearances as a starting point to argue that possibility appearances are distinct states. 'To take another example, there are equally strong connections between our apparent first-personal memories and our beliefs about the past. If someone has an apparent first-personal memory, it thereby appears to the person that a certain event once occurred; and those appearances amount to more than mere beliefs or mere inclinations to form beliefs. Part of what it is for apparent first-personal memories to involve appearances of pastness is for the former to feature states which have the same assertoric force as belong to beliefs to the effect that something once happened. Again, the matching force of the appearances figuring in apparent first-personal memories and beliefs about the past means that we can easily explain our tendency to base the latter upon the former.' [13, p. 322].

${ }^{43}$ Sosa [27, p. 46].

${ }^{44}$ Compare Mark Schroeder's notion of presentational attitudes, including both belief states and perceptual states, but excluding cognitive attitudes like wondering, assuming, supposing, and imagining. [24, p. 15]. 